\title{
Elaboração de técnica para avaliar o pensamento contrafactual em adultos ${ }^{1}$
}

\section{Preparation of technique to evaluate the adults in counterfactual thinking}

\section{Preparación de técnica para evaluar los adultos en pensamiento contrafactual}

\author{
Juliana Sarantopoulos Faccioli* \\ Universidade Federal de São Carlos - UFScar, São Carlos, São Paulo, Brasil \\ Florença Lucia Coelho Justino** \\ Universidade Federal de São Carlos - UFScar, São Carlos, São Paulo, Brasil \\ Patrícia Waltz Schelini*** \\ Universidade Federal de São Carlos - UFScar, São Carlos, São Paulo, Brasil
}

\begin{abstract}
RESUMO
O pensamento contrafactual equivale a modificações mentais para eventos passados, podendo produzir consequências benéficas ou aversivas. Esse tipo de pensamento está associado a processos cognitivos como resolução de problemas, tomada de decisão, capacidade de enfrentamento, entre outros, podendo auxiliar no entendimento de grupos específicos, tais como: depressivos, esquizofrênicos e vítimas de violência. No Brasil, estudos sobre esse tipo de pensamento são muito escassos, não havendo materiais disponíveis para facilitar sua evocação. Assim, o objetivo deste estudo foi elaborar e avaliar um instrumento para acessar o pensamento contrafactual de adultos. Participaram cinco alunos de pós-graduação, capacitados para avaliar o material e as alternativas de modificação da realidade. Após a primeira avaliação, apenas sete de um total de 24 alternativas atingiram índice de concordância satisfatório, sendo necessárias quatro avaliações até que se atingisse esse índice em todas as alternativas. Ao final, o material foi constituído de cinco histórias, seguidas de perguntas de modificações livres e alternativas de modificação de aspectos da mesma. Considerando a elevada concordância entre os juízes ao final das avaliações, julgou-se o material adequado para avaliar o pensamento contrafactual de adultos.
\end{abstract}

Palavras-chave: imaginação, pensamento contrafactual, avaliação.

\section{ABSTRACT}

The counterfactual thinking are mental modifications to past events and may produce beneficial or aversive consequences. This kind of thinking is associated with cognitive processes such as problem solving, decision making, coping skills, among others, and can help to understand specific groups such as depressive, schizophrenic and victims of violence. In Brazil, 
studies on this type of thinking are very scarce, and there are no materials available for easy recall. The aim of this study was to develop and evaluate a material to access the counterfactual thinking in adults. Participated five graduated students, trained to evaluate the material and the alternatives of modifications to reality. The agreement between the judges was paired with the original proposal of the researchers. After the first evaluation, seven of 24 alternatives reached satisfactory level of agreement, requiring four evaluations performed up to this index in all alternatives. At the end, the material consisted of five stories, followed by questions of free modifications and alternatives of modification in the story. Considering the high concordance among the judges at the end of the evaluations, it was deemed the material adequate to assess counterfactual thinking in adults.

Keywords: imagination, counterfactual thinking, assessment.

\section{RESUMEN}

El pensamiento contrafactual son modificaciones mentales de acontecimientos pasados y pueden producir consecuencias benéficas 0 aversivos. Este tipo de pensamiento se asocia con procesos cognitivos como la resolución de problemas, toma de decisiones, habilidades de afrontamiento, entre otros, y puede ayudar en la comprensión de los grupos específicos, tales como la depresión, la esquizofrenia y las víctimas de la violência. En Brasil, los estudios sobre este tipo de pensamiento son muy escasos, y no hay materiales disponibles para una fácil recuperación. El objetivo de este estudio fue desarrollar y evaluar un material a acceder los pensamientos contrafactuais de adultos. Participó cinco estudiantes de posgrado, capacitados para evaluar lo material y lãs alternativas de modificación de la realidad. El acuerdo entre los jueces fue emparejado con la propuesta original de los investigadores. Después de la primera evaluación, siete de 24 alternativas alcanzaron nivel satisfactorio de acuerdo. Necessitó de cuatro evaluaciones realizadas hasta este índice en todas las alternativas. Al final, el material consistió de cinco pisos, seguido de preguntas de modificaciones libres y alternativas de modificacion de aspectos de la historia. Teniendo en cuenta la alta concordancia entre los jueces, se consideró el material adecuado para evaluar a los pensamientos contrafactuais de adultos.

Palabras clave: imaginación, el pensamiento contrafáctico, evaluación.

\section{Introdução}

A habilidade de pensar hipoteticamente é fundamental para o raciocínio e para a tomada de decisão. As pessoas tendem a considerar alternativas hipotéticas quando pensam sobre o futuro e esses pensamentos sobre alternativas futuras auxiliam no planejamento e na predição de comportamentos. No entanto, alternativas hipotéticas também são criadas quando se pensa no passado, sendo esta a característica das alternativas contrafactuais (Byrne \& Girotto, 2009). O pensamento contrafactual (PC) vem sendo recentemente estudado por psicólogos cognitivistas, por ser considerado como uma ferramenta importante de adaptação do ser humano ao seu meio (Wong, Galinsky \& Kray, 2009). De acordo com Byrne (2002), esse tipo de pensamento se relaciona com 
pensamentos causais, propiciando às pessoas aprenderem a partir de suas experiências e influenciando diversas atividades cognitivas, desde a criatividade até os julgamentos e o processo de tomada de decisão.

O pensamento contrafactual (PC) pode ser definido, portanto, como representações mentais de alternativas para eventos, ações ou estados passados (Byrne, 2005; Roese, 1994, 1997; Epstude \& Roese, 2008). Dessa forma, os PCs são cognições sobre eventos passados que visam alterar a sequência de acontecimentos ou modificar o acontecido, com o objetivo de chegar a um desfecho diferente do que realmente ocorreu. Pensar contrafactualmente envolve a negação de um antecedente causal, sendo que esse tipo de pensamento é avaliativo, na medida em que especifica alternativas que em certa medida são tangíveis de um modo melhor ou pior do que a realidade atual.

Alguns princípios-chave parecem nortear a maneira pela qual são criadas inferências racionais sobre possibilidades contrafactuais (Byrne, 2005; Byrne \& Girotto, 2009). O primeiro desses princípios, segundo Byrne e Girotto (2009), seria o princípio da verdade, que estabelece que as pessoas pensam em possibilidades verdadeiras em detrimento das falsas. O segundo princípio que norteia a consideração de possibilidades é o princípio da parcimônia, que postula que, devido às limitações da memória de trabalho, poucas possibilidades são consideradas quando se pensa em alternativas à realidade.

Byrne (2005) ainda afirma que existem regularidades entre as modificações feitas por diferentes indivíduos, o que parece indicar pontos da realidade que atraem com maior frequência a atenção das pessoas. Esses pontos são denominados linhas de falha da realidade e constituem aspectos dos fatos reais que parecem mais mutáveis do que outros e determinam o conteúdo das elaborações contrafactuais. Muitas pessoas focam-se em eventos excepcionais, que saem da normalidade ao invés de eventos rotineiros (Kahneman \& Miller, 1986; Kahneman \& Tversky, 1982b citados por Byrne \& Girotto, 2009). Portanto, um importante tipo de evento que as pessoas modificam quando elaboram alternativas contrafactuais é o chamado evento não usual ou excepcional. Quando uma pessoa se engaja na elaboração de um pensamento contrafactual, o foco geralmente recai em eventos que fogem da normalidade (Byrne, 2005; Kahneman \& Tversky, 1982 como citado em Byrne \& Girotto, 2009).

De acordo com Byrne (2005), as pessoas tendem a gerar mais pensamentos contrafactuais quando realizam uma ação do que quando deixam de realizá-la (inação). Isso acontece porque há uma tendência para se arrepender mais de ações que levam a um resultado indesejado do que inações. A elaboração de alternativas à realidade aparece com mais frequência após uma ação porque, 
quando as pessoas percebem a ação, mantém na mente também a negação dessa ação, o que leva a uma dupla possibilidade (Byrne, 2005).

Além disso, pesquisas evidenciam que as pessoas tendem a imaginar alternativas para eventos que estão sob seu controle com mais frequência do que para aqueles que estão fora do controle (Girotto, Legrenzi, \& Rizzo, 1991; Byrne, 2005). Estudos que verificavam a mutabilidade de uma ação controlável levantaram a ideia de que o que as pessoas modificam não é apenas a ação controlável, mas a situação socialmente inaceitável que envolve o evento controlável (McCloy \& Byrne, 2000). Situações proibidas acarretam em obrigações pessoais e sociais, como ajudar uma vítima de ataque cardíaco, ou doar um órgão a um parente. Dessa forma, situações socialmente inapropriadas que levam a um resultado negativo são mais comumente modificadas pelas pessoas do que ações socialmente apropriadas. A elaboração de PCs, portanto, também é influenciada por convenções sociais e regulações culturais. Byrne (2005) denomina esse aspecto da realidade de "obrigação", que pode ser descrita como o que é permitido e o que é proibido de acordo com as normas sociais de um dado grupo ou cultura.

Outra linha de falha da realidade refere-se ao tempo, uma vez que as pessoas representam as possibilidades na ordem temporal em que os eventos ocorrem. A ordem temporal pode afetar o que é mais prontamente modificado quando alternativas são imaginadas. As pessoas tendem a pensar em alternativas para eventos mais recentes, por exemplo, perder um avião pelo atraso de 5 minutos pode evocar mais pensamentos contrafactuais do que perdê-lo por um atraso de uma hora (Byrne, 2005; Kaheman \& Miller, 1986, como citado em Wong, Galisky \& Kray, 2009; Roese \& Olson, 1995).

O último aspecto abordado por Byrne (2005) é a questão da relação entre pensamentos contrafactuais e pensamentos causais, ou seja, os fatos modificados são vistos como a causa de determinada consequência. Quando uma pessoa cria uma alternativa imaginária, há a identificação de um importante fator na sequência causal dos eventos. Na sentença "se ao menos eu não tivesse deixado a janela do banheiro aberta, o ladrão não teria entrado na casa" as pessoas tendem a acreditar que o ladrão entrou na casa porque a janela foi deixada aberta (Byrne, 2005; Roese, 1997).

Técnicas distintas têm sido utilizadas para avaliar o PC em diferentes grupos populacionais. Quando ocorre uma demanda de resposta a metas, indagações e intenções, esse tipo de pensamento é facilmente elaborado, ou seja, aparece de forma espontânea, sem que seja necessário qualquer esforço cognitivo.

Em levantamento bibliográfico realizado na base de dados PsyciNFO (American Psychological Association), buscou-se recuperar artigos entre os períodos de 2010 a 2012 que apresentavam a expressão 
counterfactual thinking no título e como termo de indexação com o intuito de verificar o tipo de procedimento adotado para acessar o pensamento contrafactual. Observou-se que diferentes métodos foram utilizados para acessar esse tipo de pensamento e foram criadas cinco categorias para nomear os métodos utilizados, quais sejam: cenários hipotéticos, autorrelato, não especificado, performance em tarefa e transcrições. A categoria mais frequente foi a de cenários hipotéticos, sendo que 11 dos 25 artigos recuperados utilizaram-se desse método. Os cenários hipotéticos podem ser definidos como pequenas vinhetas ou enredos curtos que descrevem situações críticas a partir das quais há a possibilidade de elaborar uma versão alternativa para os acontecimentos. Para as demais categorias a frequência de artigos foi de seis para auto-relato, que consistia na narração de um evento ou fato da própria experiência de vida que fosse passível de alterações; quatro não especificaram o método utilizado; três solicitaram que pensamentos contrafactuais fossem elaborados a partir da performance dos participantes em uma tarefa e um deles solicitava elaboração de alternativas contrafactuais a partir das transcrições de julgamentos legais.

Segundo Juhos, Quelhas e Senos (2003), o uso de cenários padronizados permite que seja minimizada a interferência de outras variáveis no momento da elaboração do PC. Apesar de afirmar que por meio do uso de cenários é possível avaliar os PCs decorrentes das situações apresentadas, Kasimatis e Wells (1995) apontam duas limitações sobre o uso desse método. Segundo os autores, a artificialidade dos cenários hipotéticos pode levar os participantes a responder de formas hipotéticas que não correspondem a modos de ação que desempenhariam em situações reais. A segunda limitação diz respeito às questões feitas após os cenários, uma vez que fixar o número de pensamentos que podem ser listados pode levar a uma orientação forçada da situação (Kasimatis \& Wells, 1995). Os autores afirmam ainda que o modo como o pensamento contrafactual é medido influencia não só a quantidade de pensamentos contrafactuais relatados, mas também como as elaborações contrafactuais se relacionam a outras variáveis, tais como características de personalidade como a autoestima. Seus resultados indicaram que os participantes relataram mais pensamentos contrafactuais quando as instruções incluíam uma explicação sobre os contrafatos do que quando essa explicação não estava inclusa. Entretanto, apesar das limitações do uso de cenários, Kasimatis e Wells (1995) reconhecem que o uso de cenários hipotéticos permite o acesso ao PC. Byrne (2002) supõe que os resultados encontrados nas pesquisas sobre a maneira como as pessoas pensam sobre o que poderia ter acontecido (what might have been) quando são expostas a histórias fictícias podem se generalizar para a forma como as pessoas pensam sobre suas experiências pessoais. 
Estudos realizados por Faccioli e Schelini (2009) e Justino e Schelini (2010) representam as únicas pesquisas brasileiras sobre o assunto e avaliaram o PC por meio de duas técnicas distintas. Faccioli e Schelini (2009) realizaram um estudo com crianças em que elas deveriam relatar um dia típico de sua rotina e duas situações que evocassem sentimentos de raiva e tristeza, bem como montar um cenário alternativo (incluindo locais, pessoas, objetos e situações) a partir de maquetes e bonecos colocados à disposição. Por meio dessa montagem os pensamentos imaginativos alternativos à realidade seriam acessados. A maquete simulava uma cidade e protótipos de estabelecimentos comerciais, de ensino e de saúde e casas, que permitiam que o participante montasse a sua cidade e os locais que costumava frequentar. Após a montagem do cenário alternativo, era solicitado aos participantes que narrassem novamente um dia completo. Foi observado que, em relação aos elementos da maquete, não foram encontradas diferenças relevantes entre os dois cenários. As mudanças entre o dia real e o dia imaginado foram percebidas por meio das narrativas das crianças sobre o seu dia. Observou-se ainda que as mudanças tiveram função afetiva, ou seja, permitiram que os participantes se sentissem melhor com a situação desagradável e o PC ocorreu no sentido de subtrair a situação desagradável. Como crítica ao estudo desenvolvido, as autoras indicam que os participantes tenderam a se interessar pela manipulação dos objetos, mas os materiais apresentados, talvez pelo caráter extremamente lúdico, não facilitaram a expressão de pensamentos contrafactuais.

Justino e Schelini (2010) tiveram como objetivo avaliar a capacidade de modificar histórias em diferentes grupos etários (crianças, jovens adultos e idosos) em busca de possíveis diferenças no PC, verificando-se ainda se haveria relação entre experiência adquirida e - PC. A amostra foi composta por 15 participantes, de ambos os sexos divididos em três grupos de faixas etárias. Para acessar o PC, foram apresentadas quatro histórias adaptadas de contos sendo cada uma delas seguidas por quatro alternativas de modificação. As três primeiras histórias deveriam ser modificadas a partir de alternativas apresentadas e na quarta estória os participantes deveriam realizar modificações livres. Os resultados sugerem uma tendência à realização de modificações que envolvem ações e inações e na ordem temporal dos acontecimentos. Crianças apresentaram menos dificuldade na execução de modificações livres e o número de modificações realizadas por elas foi maior do que as realizadas por adultos e por idosos. Nos demais grupos, foi observado que o aspecto ação apareceu com frequência e as modificações propostas assim como no grupo das crianças tenderam a melhorar a estória. 0 tamanho reduzido da amostra não permitiu afirmar que houve diferenças no pensamento contrafactual entre os grupos. No entanto, constatou-se que há uma tendência à escolha e modificação de 
alguns aspectos em detrimento de outros, como afirma Byrne (2005). No que se refere à relação entre experiência adquirida e a elaboração de contrafatos, houve indícios de que a perspectiva individual pode afetar a elaboração de contrafatos, no entanto, não há como afirmar a extensão da influência da experiência sobre tal elaboração. A ideia do estudo desenvolvido por Justino e Schelini (2010) repercute na elaboração do material da presente pesquisa que, conforme será explicado mais adiante, também faz uso de histórias, mas se propõem a realizar uma análise minuciosa das alternativas apresentadas aos participantes, como forma de mudar partes dos enredos.

A elaboração de um material para acessar e avaliar o pensamento contrafactual em adultos se faz necessária na medida em que este tipo de cognição parece estar associado a outros processos cognitivos tais como a resolução de problemas (Epstude \& Roese, 2008), a tomada de decisão e a performance criativa (Wong, Galinsky \& Kray, 2009), bem como a capacidade de enfrentamento (coping), adaptabilidade e o funcionamento social dos indivíduos. 0 conhecimento sobre esse tipo de pensamento pode auxiliar, inclusive, no entendimento da cognição de grupos específicos, tais como, casos de saúde mental (depressivos, ansiosos, esquizofrênicos) e mulheres vitimizadas, ou pessoas que passaram por diferentes experiências traumáticas em suas vidas, com o intuito de verificar a atuação desse tipo de cognição e a influência de experiências específicas na elaboração e ativação das cognições sobre eventos passados. Além disso, observou-se que devido à escassez de estudos sobre o tema dentro do contexto brasileiro, fazia-se necessária a elaboração de uma técnica destinada a facilitar 0 acesso aos pensamentos contrafactuais e também a avaliar quais tipos de PCs são mais frequentemente emitidos no nosso contexto.

Desta forma, o presente estudo tem o objetivo de elaborar uma técnica para acessar os pensamentos contrafactuais de adultos, bem como analisar a concordância de especialistas em relação às alternativas de modificação da realidade, incluídas em tal técnica.

\section{Método}

\subsection{Participantes}

A amostra de juízes especialistas foi constituída por cinco estudantes de pós- graduação em Psicologia, sendo quatro de mestrado e um de doutorado, todos de uma universidade pública do interior do estado de São Paulo.

\subsection{Materiais}


A capacitação de juízes foi realizada em uma sala anexa ao Departamento de Psicologia de uma universidade pública do interior do estado de São Paulo, a qual dispunha de equipamento de mídia com projetor.

\subsection{Instrumentos}

Foi utilizada uma Carta ao Juiz, para explicar como seria feita a avaliação do material; um conto seguido por quatro alternativas de modificação, retirado do estudo de Justino e Schelini (2010), que foi utilizado como exercício de treino de avaliação; e o material elaborado para o acesso do pensamento contrafactual. Este material foi constituído por (1) um quadro que sumarizava os principais aspectos modificáveis da realidade, descritos em 2005 por Byrne (ação/inação, obrigação, tempo, evento não-usual), com a definição dos mesmos e um exemplo de cada um e (2) cinco histórias seguidas de quatro alternativas de modificação. Cada alternativa representava um aspecto modificável da realidade, citado por Byrne (2005).

Para a elaboração do material de avaliação do pensamento contrafactual em adultos, optou-se pelo uso de notícias adaptadas de jornais e revistas e cenários hipotéticos adaptados da literatura (McCloy \& Byrne, 2000; Juhos et al., 2003), por se considerar que os enredos narrados se aproximariam mais aos fatos que acontecem na realidade dos participantes e a riqueza de detalhes das narrativas poderiam permitir algumas possibilidades de modificação.

Na Figura 1, é apresentada, como exemplo, a primeira história (A Tentação, adaptada do estudo de Juhos et al., 2003) com suas respectivas questões abertas e alternativas de modificação da realidade. Vale lembrar que para as demais histórias, o que variou foram apenas as alternativas de modificação da realidade, já que estas se referiam aos conteúdos de cada enredo. 


\section{HISTÓRIA 1: A Tentação}

Uma grande amiga sua, que é um pouco timida com rapazes, te convida para ir com ela e com um rapaz, o Joǰo, a uma festa. Como de costume, vocè aceita o convite. Ultimamente, sua amiga e Joào estào passando muito tempo juntos, porém, esta foi a primeira vez que eles combinaram de sair à noite. Antes de sairem, sua amiga te conta que está perdidamente apaixonada por ele.

Durante a festa, você percebe que Joào é muito atraente e, além disso, está interessado em você, e isso te agrada muito. No fim da noite, sem pensar, você passa o seu nuimero de telefone para ele. Quando chega o fim de semana, Joào telefona e te convida para jantar. Vocé acaba aceitando o convite. Pouco antes de vocé sair de casa, sua amiga telefona e conta chorando que João evitou falar com ela durante toda a semana e cancelou a ida ao cinema que haviam combinado antes da festa porque tinha muita coisa para fazer.

Adaptada de Juhos, C,; Quelhas, A. C.; Senos, J (2003). QUESTÓES - HISTÓRIA 1

1) Enquanto vocé lia a históna, ocorreu algum pensamento sobre o que estava lendo?

2) Imagine se essa situação acontecesse com vocè. As pessoas, após passarem por situaçòes como essas, têm, frequentemente, pensamentos sobre como as coisas poderiam ter acontecido de outra maneira. Se vocé passasse pela mesma situação, será que pensaria em alguma coisa diferente em relação ao que aconteceu? Pense o que poderia ser diferente para que a história tenha um fim diferente. Se vocé pudesse mudar alguma coisa nessa situação, o que mudaria?

\section{ALTERNATIVAS - HISTORIA 1}

3) Ainda se colocando no lugar da narradora, qual das alternativas abaixo sena mais próxima com aquilo que você mudaria? Escolha apenas uma alternativa.

a) Eu não teria ido à festa e nem conheceria o João.

b) Eu não teria dado meu número de telefone para o paquera de minha amiga.

c) João me convidaria para sair antes da minha amiga contar que estava apaixonada por ele.

d) Eu não teria saido com minha amiga, como sempre fazia, e nào teria conhecido Joào.

Figrara 1. Exemplo de uma história com suas respectivas questões abertas e alternativas de múltipla escolha.

Para compor a primeira versão do material, buscou-se notícias de jornais e revistas que fossem contadas de maneira linear e que tivessem descrição rica dos fatos ocorridos, bem como as consequências dos eventos descritos. Após a seleção das notícias, foram elaboradas perguntas abertas que levassem o participante a pensar sobre o conteúdo lido e sobre possíveis modificações na história. Adicionalmente, foram formuladas quatro alternativas de modificação referentes aos acontecimentos de cada enredo. A primeira pergunta aberta se referia a pensamentos livres a respeito das histórias e visava verificar se 0 participante formularia, espontaneamente, pensamentos contrafactuais a partir do que havia lido. Assim, formulou-se a pergunta: "Enquanto você lia a história, ocorreu algum pensamento sobre o que estava lendo? Qual?".

Em seguida, o questionário direcionava o participante a pensar sobre o que poderia ser diferente na história, por meio da pergunta: "Imagine se essa situação acontecesse com você. As pessoas, após 
passarem por situações como essas, têm, frequentemente, pensamentos sobre como as coisas poderiam ter acontecido de outra maneira. Se você passasse pela mesma situação, será que pensaria em alguma coisa diferente em relação ao que aconteceu? Pense o que poderia ser diferente. Se você pudesse mudar alguma coisa nessa situação, o que mudaria?" Por fim, o participante deveria escolher uma alternativa de modificação, mesmo que espontaneamente não tenha pensado em alguma alternativa. Havia a opção também de não escolher nenhuma das alternativas apresentadas, caso o participante julgasse que aquelas apresentadas não condiziam com o que ele estava pensando.

Em relação mais especificamente às alternativas formuladas previamente e que possibilitariam modificações nas histórias, vale dizer que elas corresponderam às modificações de fatos baseados nas linhas de falhas da realidade descritas por Byrne (2005). Assim, cada história contou com quatro alternativas de mudanças em fatos que se referem à ação/inação, ao tempo, à obrigação e a evento não usual. A categoria "causa", também descrita por Byrne (2005), foi eliminada das alternativas, por se considerar que todas as modificações formuladas continham a ideia da relação causal, ou seja, quaisquer mudanças nos eventos das histórias eram percebidas como a causa de um resultado indesejado, que seria alterado pelo pensamento contrafactual e, como afirma a própria autora, todo pensamento contrafactual é um pensamento que envolve uma relação causal.

\subsection{Procedimento}

O projeto de pesquisa foi encaminhado e aprovado pelo Comitê de Ética em Pesquisa com Seres Humanos (CAAE 0176.0.135.00-11 e CAAE 04658812.7.0000.5504). Inicialmente, foi elaborado o material a ser avaliado pelos cinco juízes para que, em seguida, houvesse uma capacitação dos mesmos considerando o desconhecimento de especialistas brasileiros para a temática do PC, o que proporcionaria uma adequada análise de todo o material de acesso do pensamento contrafactual de pessoas adultas.

Com o material preparado, foram contatados cinco alunos da pósgraduação em Psicologia que teriam a função de juízes, ou seja, avaliariam o material, as instruções e as alternativas propostas. Todos assinaram o termo de consentimento livre e esclarecido (TCLE) para a participação na capacitação. Os juízes foram capacitados em relação ao tema, devido ao desconhecimento da existência de especialistas em pensamento contrafactual no Brasil.

O principal objetivo da avaliação do material pelos juízes foi o de verificar se as alternativas de respostas de múltipla escolha faziam referência aos aspectos da realidade propostos pelas autoras. Para possibilitar este tipo de análise do material, foi realizada uma 
capacitação dos juízes a respeito do pensamento contrafactual, em que foi feita uma apresentação explicitando o que é o pensamento contrafactual, qual sua importância, as classificações e os subtipos descritos na literatura, quais sejam: estrutura (adição, subtração e substituição), direção da comparação (ascendente e descendente) e função (afetiva e preparatória) e, ainda, os aspectos da realidade mais comumente modificados (ação/inação, obrigação, causa, tempo e evento não usual).

Epstude e Roese (2008) afirmam que a especificação de tipos de contratatos é relevante na medida em que permite identificar a utilidade de determinados tipos para a regulação do comportamento. No que se refere à estrutura, a construção de contrafatos se dá por meio da adição, subtração ou substituição de elementos antecedentes. Nos contrafatos aditivos, elementos são adicionados àqueles que já estavam presentes na realidade e o foco está em fazer algo que de fato ainda não havia sido feito. Os contrafatos subtrativos focam na eliminação ou remoção de alguma coisa que foi feita ou aconteceu e os contrafatos substitutivos focam na troca de um antecedente por outro. Com relação à direção da comparação das alternativas contrafactuais com a realidade, os PCs podem ser classificados em subtipos ascendentes e descendentes. Os pensamentos contrafactuais ascendentes podem ser definidos como aqueles que descrevem alternativas melhores do que aquilo que realmente aconteceu e os descendentes, descrevem alternativas que são piores do que a realidade (Roese, 1994). Essa classificação enfatiza a melhoria ou a preservação do status quo, ou seja, enquanto os pensamentos contrafactuais ascendentes podem dizer como ir adiante, os descendentes dizem como as coisas podem continuar piorando.

De acordo com Roese (1994), o pensamento contrafactual (PC) tem duas funções, quais sejam preparatória e afetiva, sendo que os subtipos específicos de PC estariam relacionados a cada uma dessas funções. A função preparatória relaciona-se a melhorias para o comportamento futuro e está relacionada aos pensamentos contrafactuais ascendentes em oposição aos descendentes. As alternativas ascendentes levam em consideração esquemas para futuras ações que salientam os aspectos necessários para que o sucesso de uma ação seja obtido no futuro. A função afetiva faz referência ao se sentir melhor diante de alternativas imaginadas para eventos que já ocorreram. Roese (1994) afirma que via efeito de contraste, os pensamentos contrafactuais descendentes eliciam afeto positivo, como alívio, por exemplo, enquanto os contrafatos ascendentes podem eliciar afeto negativo, como por exemplo, decepção.

Durante a capacitação, além da explanação detalhada sobre o tema, cada aspecto abordado foi exemplificado e discutido e, ao final, foi 
realizada uma atividade que tinha por objetivo treinar os juízes para a avaliação do material. Essa atividade foi composta de uma fábula que continha quatro alternativas de modificação, retirada do estudo de Justino e Schelini (2010). Após lerem a fábula, os juízes deveriam classificar cada uma das alternativas sugeridas com relação ao aspecto da realidade (ação/inação, tempo, obrigação, causa ou evento não-usual) ao qual faziam referência. Dessa maneira, os juízes puderam entender como deveriam avaliar o material e tirar suas dúvidas quanto ao procedimento. Vale ressaltar que as alternativas poderiam apresentar mais de um aspecto, sendo que os juízes deveriam apontar qual aspecto era mais proeminente em cada sentença.

Cada juiz, individualmente, recebeu um caderno composto por uma tabela que sumarizava os principais aspectos da realidade, uma breve definição dos mesmos com um exemplo de cada e as cinco histórias seguidas de quatro alternativas de modificação. Após a primeira avaliação, foi feito um encontro para discutir a mesma e tirar dúvidas quanto a algumas observações feitas por eles. Foi adotado o nível de concordância de $80 \%$ entre juízes para que a alternativa fosse considerada como classificada dentro do aspecto da realidade proposto. Depois da primeira análise dos juízes, as alternativas com baixo índice de concordância foram reformuladas e entregues para uma nova avaliação. Foram realizadas quatro avaliações, de modo que o índice de concordância de $80 \%$ para cada alternativa fosse atingido.

Antes da segunda avaliação foram incluídos dois cenários adaptados de estudos da literatura (Juhos et al., 2003 e Byrne, 2005), utilizados para acessar e avaliar o pensamento contrafactual. Para esses dois cenários também foram formuladas quatro alternativas de modificação, que foram avaliadas pelos juízes a partir da segunda avaliação. Após as avaliações dos juízes, o material foi sendo readequado e a versão final foi composta por cinco histórias, duas adaptadas de cenários da literatura e três de jornais e revistas.

\section{Resultados e discussão}

A análise da concordância de itens ou questões de um instrumento é tida como um critério de decisão sobre a pertinência do item ao traço a que teoricamente se refere (Pasquali, 1999). Por se tratar de uma nova técnica para acessar os pensamentos contrafactuais, julgou-se fundamental que juízes analisassem o material produzido, justamente para proporcionar a compreensão de que os itens elaborados eram adequados ao acesso do pensamento contrafactual de adultos e à avaliação de seus diversos tipos. 
A avaliação dos juízes foi fundamental para aprimorar o material. Os juízes sugeriram diminuir o tamanho de algumas histórias, alterar alguns termos para facilitar o entendimento dos participantes e modificar o tempo verbal das alternativas do pretérito para 0 pretérito imperfeito. Em relação à avaliação das alternativas, foi contabilizada a frequência de respostas dos juízes para cada alternativa e calculado um índice de concordância entre juízes. $O$ índice de concordância foi considerado satisfatório quando quatro, dos cinco juízes classificavam a alternativa dentro da mesma categoria, isto porque este índice é tido como suficientemente adequado quando igual ou superior a $80 \%$ (Pasquali, 1999). Quando a concordância apresentou um índice menor, a alternativa foi reformulada e submetida a novas avaliações. Em seguida, foi verificado se havia concordância entre a avaliação dos juízes e a classificação inicial das alternativas proposta pelas autoras. Foram necessárias quatro avaliações para que se chegasse ao índice de concordância satisfatório para todas as alternativas.

A Tabela 1 apresenta a distribuição das histórias que foram apresentadas para apreciação em cada uma das quatro avaliações. As colunas apresentam as avaliações realizadas pelos juízes e as linhas, as histórias que fizeram parte de cada uma delas. Os traços representam a ausência de determinada história na avaliação ou a exclusão da mesma após determinada avaliação.

Tabela 1

\begin{tabular}{|c|c|c|c|}
\hline Avaliação 1 & Avaliação 2 & Avaliaçào 3 & Avaliação 4 \\
\hline- & A tentação & A tentação & A tentação \\
\hline - & No caminho de casa & No caminho de casa & No caminho de casa \\
\hline Dilema da montanha & Dilema da montanha & Dilema da montanha & Dilema da montanha \\
\hline $\begin{array}{l}\text { A vida após o } \\
\text { corredor da morte }\end{array}$ & - & - & - \\
\hline $\begin{array}{l}\text { Oencantador de } \\
\text { plateias }\end{array}$ & $\begin{array}{l}\text { O encantador de } \\
\text { plateias }\end{array}$ & $\begin{array}{l}\text { O encantador de } \\
\text { plateias }\end{array}$ & - \\
\hline Renascido para viver & Renascido para viver & Renascido para viver & Renascido para viver \\
\hline $\begin{array}{l}\text { Celular e elevador } \\
\text { salvam vida de } \\
\text { ajudante de obras em } \\
\text { desabamento no Rio. }\end{array}$ & $\begin{array}{l}\text { Celular e elevador } \\
\text { salvam vida de } \\
\text { ajudante de obras em } \\
\text { desabamento no Rio. }\end{array}$ & $\begin{array}{l}\text { Celular e elevador } \\
\text { salvam vida de } \\
\text { ajudante de obras em } \\
\text { desabamento no Rio. }\end{array}$ & $\begin{array}{l}\text { Celular e elevador } \\
\text { salvam vida de } \\
\text { ajudante de obras em } \\
\text { desabamento no Rio. }\end{array}$ \\
\hline
\end{tabular}

Distribuição das histórias em cada uma das quatro avaliações.

A partir da Tabela 1, percebe-se que na Avaliação 1, os juízes avaliaram cinco histórias adaptadas e suas respectivas alternativas de modificação que faziam referência aos aspectos da realidade. A história "A vida após o corredor da morte" foi indicada por três dos cinco juízes para ser retirada do material, uma vez que os aspectos contidos nela (pena de morte) não representavam o contexto brasileiro. $\mathrm{Na}$ segunda avaliação foram incluídas duas histórias 
retiradas dos estudos de Juhos et al. (2003) e de McCloy e Byrne, 2000. Optou-se pela inclusão destas histórias, primeiramente, por já estarem descritas na literatura como materiais utilizados para avaliação do pensamento contrafactual e pela necessidade de apresentar aos participantes narrativas que pudessem se aproximar ao seu cotidiano. Após a terceira avaliação, duas das quatro alternativas da história "O encantador de plateias" não atingiram o nível de concordância satisfatório $(80 \%)$ e optou-se por excluir essa história do material. O material final foi composto por cinco histórias: duas adaptadas de cenários e três adaptadas de notícias de jornais e revistas.

Na Tabela 2 são apresentadas as quatro avaliações dos juízes para cada uma das alternativas, no que se refere aos aspectos da realidade. A legenda da tabela indica quais aspectos da realidade cada uma das letras fazem referência a. As letras referem-se à categoria resultante da apreciação dos juízes indicando qual a classificação da alternativa de acordo com a avaliação dos mesmos quando ela diferia da classificação proposta pelas autoras.

Tabela 2

Índice de concordância das alternativas analisadas pelos juízes nas quatro avaliações.

\begin{tabular}{|c|c|c|c|c|c|c|c|c|c|c|}
\hline \multirow[b]{2}{*}{ História } & \multirow[b]{2}{*}{ Alteruativa } & \multirow{2}{*}{$\begin{array}{c}\text { Classificaçào } \\
\text { proposta }\end{array}$} & \multicolumn{2}{|c|}{ AVALIAC̣AO 1} & \multicolumn{2}{|c|}{ AVALLACCOO2 } & \multicolumn{2}{|c|}{ AVALIACCAO 3} & \multicolumn{2}{|c|}{ AVALLAÇAO 4} \\
\hline & & & Juizes & $\begin{array}{l}\text { Concordancia } \\
\text { com autoras }\end{array}$ & Juizes & $\begin{array}{l}\text { Concordáncia } \\
\text { com autoras }\end{array}$ & Juizes & $\begin{array}{l}\text { Coucordancia } \\
\text { com autoras }\end{array}$ & Juizes & $\begin{array}{l}\text { Concordáncia } \\
\text { com autoras }\end{array}$ \\
\hline \multirow{4}{*}{$\underset{\text { Tentaçaio }}{\text { A }}$} & A & Açāo/nasçẩo & - & - & $80 \%$ & $\operatorname{sim}$ & - & - & - & - \\
\hline & B & Obrignçâo & - & - & $80 \%$ & Sim & - & - & - & - \\
\hline & c & Tempo & - & - & $40 \%$ & $\operatorname{Sin}$ & $100 \%$ & Sim & - & - \\
\hline & $D$ & Evento กล̃o นต่งaI & - & - & $60 \%{ }^{\circ}$ & Nâo & $100 \%$ & Sim & - & - \\
\hline \multirow{4}{*}{$\begin{array}{l}\text { No } \\
\text { caminho } \\
\text { de casa }\end{array}$} & A & Tempo & - & - & $60 \%$ & Sim & $100 \%$ & $\operatorname{Sim}$ & - & - \\
\hline & B & Obrigaçâo & - & - & $80 \%$ & $\operatorname{Sim}$ & - & - & - & - \\
\hline & c & Evento aลิo usuaม & - & - & $60 \%$ & Sim & $100 \%$ & Sim & - & - \\
\hline & D & Açãolinaçāo & - & - & $80 \%$ & Sim & - & - & - & - \\
\hline \multirow{4}{*}{$\begin{array}{l}\text { Dilema da } \\
\text { montanha }\end{array}$} & A & Evento nhio usual & $80 \%$ & Sim & - & - & - & - & - & - \\
\hline & B & Ação/nação & $80 \%$ & Sim & - & - & - & - & - & - \\
\hline & c & Obrigaçâo & $80 \%$ & Sim & - & - & - & - & - & - \\
\hline & D & Tempo & $80 \% \%^{\circ}$ & Nào & $80 \%$ & Sim & - & - & - & - \\
\hline \multirow{4}{*}{$\begin{array}{l}\text { Renascido } \\
\text { para viver }\end{array}$} & A & Ação/Inaçào & $80 \%^{*}$ & Nào & $80 \%$ & Sim & - & & - & - \\
\hline & B & Tempo & $60 \%$ & $\operatorname{Sim}$ & $80 \%$ & $\operatorname{Sim}$ & - & - & - & - \\
\hline & c & Obrignçầ & $60 \%$ & Sim & $100 \%$ & Não & $80 \%$ & Sim & - & - \\
\hline & D & Evento nào usual & $40 \%$ & Sim & $20 \%$ & $\operatorname{Sin}$ & $20 \%$ & $\operatorname{Sim}$ & $100 \%$ & $\operatorname{Sin}$ \\
\hline \multirow{4}{*}{$\begin{array}{c}0 \\
\text { encantadot } \\
\text { de plateias }\end{array}$} & A & Obriznção & $60 \% \%^{\circ}$ & Năo & $60 \% \%^{\circ}$ & Nào & $40 \%$ & $\operatorname{Sim}$ & $\cdot$ & - \\
\hline & B & Evento nâo usนaล & $60 \%$ & Sim & $20 \%$ & Sim & $40 \%$ & Sim & - & $=$ \\
\hline & c & Tempo & $60 \% \%^{\circ}$ & Näo & $100 \%$ & Nâo & - & $\operatorname{Sim}$ & - & - \\
\hline & D & Açào/lnação & $100 \%$ & Sim & - & Sim & - & - & - & - \\
\hline \multirow{4}{*}{$\begin{array}{l}\text { Celulare } \\
\text { elevador }\end{array}$} & A & Tempo & $80 \% \%^{4}$ & Sim & - & Sim & - & - & - & - \\
\hline & B & Açāo/Inaçāo & $20 \%$ & Sim & $60 \%$ & $\operatorname{Sim}$ & $100 \%$ & $\operatorname{Sim}$ & - & - \\
\hline & c & Obrizaçấo & $100 \% \%^{\circ}$ & Nâo & $40 \%$ & Nâo & $80 \%$ & Sim & - & - \\
\hline & D & Evento nhio usual & $20 \%$ & $\operatorname{Sim}$ & $20 \%$ & Sim & $60 \%$ & Sim & $100 \%$ & Sim \\
\hline
\end{tabular}

Por meio da Tabela 2, nota-se que das 16 alternativas propostas inicialmente, apenas oito obtiveram índice de concordância igual ou maior a $80 \%$, na primeira avaliação. Dessas alternativas, três 
apresentaram discordância com a classificação proposta pelas autoras (alternativa " $D$ " da história "Dilema da montanha", alternativa " $A$ " da história "Renascido para viver" e a alternativa " $C$ " da história "Celular e elevador salvam ajudante de obras no Rio"), que foram classificadas pelos juízes como se referindo ao aspecto ação/inação. Nos casos em que não ocorreu a concordância entre a avaliação dos juízes e a proposta inicial das autoras, dois procedimentos distintos foram adotados. Quando houvesse alta concordância entre juízes para duas alternativas no mesmo aspecto da realidade e uma delas concordasse com a proposta das autoras a alternativa que não foi classificada de acordo com a proposta inicial seria reformulada para que se adequasse a mesma. Por exemplo, a alternativa " $D$ " da história "Dilema da montanha" recebeu $80 \%$ de concordância entre juízes para o aspecto ação/inação, apesar da classificação proposta pelas autoras ser tempo. Como a alternativa proposta para esse aspecto ("B") já havia obtido a concordância entre juízes necessária, a alternativa " $D$ " foi reformulada para se adequar ao aspecto tempo.

Caso a alternativa não obtivesse concordância satisfatória para o aspecto proposto, mas obtivesse a concordância entre juízes satisfatória para outro aspecto, a classificação inicial seria reconsiderada de modo que se adequasse à classificação dos juízes. Esse é o caso da alternativa "A" da história "Renascido para viver". Inicialmente, a proposta de classificação para essa alternativa era o aspecto obrigação, e para a alternativa "C", ação/inação. Entretanto, após a avaliação dos juízes, houve concordância de $80 \%$ na alternativa " $\mathrm{A}$ " para $\mathrm{O}$ aspecto ação/inação, enquanto que a alternativa " $C$ " obteve apenas $60 \%$ de concordância para esse aspecto. Dessa forma, foi mantida a classificação atribuída pelos juízes (ação/inação) para a alternativa " $A$ " e a alternativa " $C$ " foi reformulada para se adequar a classificação faltante, obrigação. $\mathrm{Na}$ Tabela 2, a alternativa " $A$ " da história "Renascido para viver" referese à classificação mantida de acordo com a concordância entre juízes, e não classificação proposta inicialmente (obrigação). Optou-se por deixar a classificação dos juízes na tabela, para ficar condizente com a classificação da alternativa na composição final do material.

Das três alternativas que obtiveram concordância alta entre juízes e que não concordaram com a proposta inicial das autoras, apenas uma foi mantida conforme a classificação dos juízes, não sendo necessária sua reavaliação. As outras duas foram reformuladas para serem novamente avaliadas pelos juízes.

Além disso, as oito alternativas que não obtiveram índice de concordância satisfatório entre juízes (menor que $80 \%$ ) foram reformuladas para que ficassem mais proeminentes os aspectos da realidade propostos pelas autoras. Todas as alternativas foram reescritas no pretérito imperfeito. Após a primeira avaliação e as 
readequações realizadas, cinco alternativas não precisaram ser reavaliadas na segunda avaliação.

$\mathrm{Na}$ segunda avaliação, foi solicitado que os juízes reavaliassem as alternativas que não haviam atingido o índice de concordância satisfatório. O material sofreu alteração na sua estrutura: optou-se por incluir questões para modificações livres após cada um dos enredos antes da apresentação das alternativas para modificação e foram incluídos os dois cenários adaptados da literatura, como já citado anteriormente. A inserção de questões abertas após cada história teve o intuito de possibilitar a comparação entre os pensamentos contrafactuais espontâneos e as elaborações contrafactuais que seriam escolhidas nas alternativas de modificação. As questões abertas inseridas foram (1) Enquanto você lia a estória, ocorreu algum pensamento sobre o que estava lendo?, (2) Como você se sentiu ao ler a estória? e (3) Como os fatos dessa estória poderiam ser diferentes? Se você pudesse mudar algum aspecto em como as coisas aconteceram na estória, o que mudaria?. Portanto, todas as histórias foram seguidas de perguntas abertas sobre pensamentos que ocorreram durante a leitura, sentimentos evocados e possíveis modificações no curso dos acontecimentos do enredo.

A partir da Tabela 2 é possível observar que das 10 alternativas reavaliadas na segunda avaliação ( 8 alternativas que não alcançaram o índice de concordância necessário e 2 que não concordaram com a classificação proposta pelas autoras), duas apresentaram índices de concordância satisfatórios e concordância com a classificação inicial proposta pelas autoras (alternativa "D" - Dilema da Montanha e alternativa "B"- Renascido para viver). A alternativa " $C$ " do enredo "Renascido para viver", que obteve $100 \%$ de concordância para um aspecto diferente do proposto inicialmente (causa), foi reformulada para fazer referência ao aspecto obrigação. O mesmo ocorreu com a alternativa " $A$ " de "O encantador de plateias". As demais alternativas foram readequadas de modo que a probabilidade de fazerem referência ao aspecto da realidade no qual foram classificadas fosse aumentada na terceira avaliação.

Ainda na segunda avaliação, é possível observar, por meio da Tabela 2 , que, no que se refere ao primeiro cenário ("A tentação") apenas duas alternativas não obtiveram índice de concordância satisfatório. Dessas, a alternativa $D$, apresentou discordância com a classificação inicial proposta pelas autoras, concordando para a categoria causa. Essas duas alternativas foram readequadas de modo que pudessem se aproximar do aspecto da realidade ao qual faziam referência e passaram por uma nova avaliação. No que se refere ao segundo cenário, duas alternativas (" $A$ " e " $C$ ") não atingiram o índice de concordância satisfatório e também foram reformuladas.

$\mathrm{Na}$ terceira avaliação, as definições de cada um dos aspectos da realidade foram aprimoradas e apresentadas aos juízes em uma nova 
tabela. Foram apresentadas apenas as alternativas que precisavam da terceira avaliação e as mudanças realizadas estavam destacadas. Optou-se por retirar das opções de classificação de juízes a categoria causa, dado que todas as alternativas apresentavam relações causais entre eventos.

Ainda a partir da Tabela 2, é possível observar que 11 alternativas foram revistas na terceira avaliação. Destas 11 , cinco atingiram 0 nível de concordância de $100 \%$, duas atingiram o nível de concordância satisfatório de $80 \%$, três atingiram um nível de concordância médio que variou entre 40 e $60 \%$ e uma atingiu um nível de concordância baixo, de $20 \%$. Essas alternativas foram mais uma vez reformuladas, de forma a assegurar um maior índice de concordância entre os juízes. Como forma de diminuir o número de histórias no material, foi retirada, após a terceira avaliação, a história "O encantador de plateias", que não havia alcançado o índice de concordância necessário para duas alternativas.

A quarta avaliação foi realizada para que as duas alternativas que não atingiram o nível de concordância satisfatório nas avaliações anteriores pudessem ser reavaliadas de modo que a concordância fosse atingida. Após a quarta avaliação, as 20 alternativas que compuseram a versão final do material apresentaram índice de concordância satisfatório. As histórias que compuseram a versão final do material podem ser observadas na Figura 2.

\begin{tabular}{|cll|}
\hline História & Título & Fonte \\
\hline 1 & A Tentação & Juhos et al. (2003). \\
2 & No caminho de casa & McCloy e Byrne (2000). \\
3 & Dilema da montanha & $\begin{array}{l}\text { Miranda (2011). Revista } \\
\text { Superinteressante -Edição especial } \\
\end{array}$ \\
& & (dezembro). \\
4 & Renascido para viver & Miranda (2011). Revista \\
& & Superinteressante - Edição especial \\
& & (dezembro). \\
& & http://g1.globo.com/rio-de- \\
5 & Celular e elevador salvam & janeiro/noticia/2012/01. \\
& ajudante de obras no Rio & \\
Figura 2. Historias presentes na versão final do material.
\end{tabular}

Considerando a elevada concordância entre os juízes, julgou-se que o material elaborado encontrava-se adequado para ser apresentado a outros participantes, de modo que os pensamentos contrafactuais 
possam ser acessados e que seja possível obter quais os aspectos da realidade mais frequente modificados.

\section{Considerações finais}

O estudo contribuiu para o desenvolvimento de uma metodologia, adaptada à realidade brasileira, para acessar e avaliar os pensamentos contrafactuais. De acordo com Justino, Faccioli e Schelini (2013) a análise dos juízes possibilitou um refinamento no material, tanto no que se refere às histórias em si, quanto na adequação das alternativas em relação ao aspecto da realidade ao qual deveriam se referir. Assim, após as quatro análises todas as alternativas tiveram índices de concordância entre juízes superiores a $80 \%$ em relação ao aspecto da realidade que estavam modificando.

A inserção de dois cenários já utilizados em estudos anteriores (McCloy \& Byrne, 2000; Juhos et al., 2003) fez-se necessária na medida em que foi constatada a importância de apresentar aos participantes relatos mais próximos de seu cotidiano e da sua realidade, 0 que poderia facilitar a elaboração de alternativas contrafactuais. Com o uso das histórias, seguidas de questões abertas e de múltipla escolha a respeito dos fatos relatados, pretende-se acessar os pensamentos contrafactuais elaborados espontaneamente e de forma direcionada com o intuito de comparar os dois tipos de elaborações em grupos específicos tais como depressivos e mulheres vitimizadas e verificar se há um padrão na elaboração desse tipo de cognição. O estudo do pensamento contrafactual em grupos específicos parte do pressuposto de que variáveis individuais estão relacionadas com a geração de tipos específicos de contrafatos e influenciam na função adaptativa ou disfuncionalidade de tal pensamento. A análise desse tipo de cognição pode dar indícios da função e ainda das diferentes formas que os grupos têm em perceber e modificar seus pensamentos em relação à realidade vivida. A análise do PC nessas populações específicas justifica-se, portanto, uma vez que tais cognições sobre eventos passados relacionam-se diretamente às estratégias de enfrentamento (coping) dos indivíduos diante de suas vivências, sejam elas traumáticas ou não. A consideração de alternativas contrafactuais permitiria modelos para ações de modificação. Estudos futuros pretendem investigar as cognições sobre eventos passados nos grupos de indivíduos depressivos e vitimizados.

\section{Referências}


Byrne, R. M. J. (2002). Mental models and counterfactual thoughts about what might have been. Trends in Cognitive Sciences, 6, 426-431.

Byrne, R. M. J. (2005). The Rational Imagination: How People Create Alternatives to Reality. Cambridge, M.A: MIT Press.

Byrne, R. M., \& Girotto, V. (2009). Cognitive Processes in Counterfactual Thinking. In K. D. Markman, W. M. P. Klein, \& J. A. Suhr (Eds.). Handbook of imagination and mental simulation (pp. 151-160). New York: Psychology Press.

Epstude, K., \& Roese N. J. (2008). The functional theory of counterfactual thinking. Personality and Social Psychology Review, 12(2), 168-192.

Faccioli, J. S., \& Schelini, P. W. (2009). A imaginação de crianças com necessidades especiais. Monografia não publicada. Universidade Federal de São Carlos, São Carlos, SP, Brasil.

Girotto, V., Legrenzi, P., \& Rizzo, A. (1991). Counterfactual thinking: The role of events controllability. Acta Psychologica, 78, 111133.

Juhos, C; Quelhas, A. C., \& Senos, J. (2003). Pensamento contrafactual na depressão. Psychologica, 32(1), 199-215.

Justino, F. L. C., Faccioli, J. S., \& Schelini, P. W. (2013). Proposta de técnica para a avaliação do pensamento contrafactual em adultos. Anais do VI Congresso Brasileiro de Avaliação Psicológica e IX Congresso Iberoamericano de Diagnóstico e Evaluación Psicológica. Maceió, Alagoas, Brasil.

Justino, F. L. C., \& Schelini, P. W. (2010). Análise da capacidade de modificação de histórias em crianças, jovens adultos e idosos. Monografia não publicada. Universidade Federal de São Carlos, São Carlos, SP, Brasil.

Kasimatis, M., \& Wells, G. L. (1995). Individual differences in Counterfactul Thinking. In: N. J. Roese, \& J. M. Olson (Eds.). What might have been: the social psychology of counterfactual thinking (pp. 81-101). New Jersey: Lawrende Erlbaum Associates.

McCloy, R., \& Byrne, R. M. J. (2000). Counterfactual thinking about controllable events. Memory and Cognition, 28, 6, 1071-1078.

Miranda, M. (2011, dezembro). Dilema da montanha. Revista Superinteressante - Edição Especial, São Paulo, SP: Abril.

Miranda, M. (2011, dezembro). Renascido para viver. Revista Superinteressante - Edição Especial. São Paulo, SP: Abril.

Pasquali, L. (1999). Testes referentes ao construto: teoria e modelo de construção. In L. Pasquali (Org.). Instrumentos Psicológicos: Manual prático de elaboração (pp. 37-71). Brasília, DF: Laboratório de Pesquisa em Avaliação e Medida - LabPAM.

Roese, N. J. (1994). The functional basis of counterfactual thinking. Journal of Personality and Social Psychology, 56, 5, 805-838. 
Roese, N., \& Olson, J. M. (1995). Counterfactual thinking: A critical overview. In N. J. Roese, \& J. M. Olson (Eds.). What might have been: The social psychology of counterfactual thinking (pp. 169-197).

Roese, N. J. (1997). Counterfactual thinking. Psychological Bulletin, 121(1), 133-148.

Wong, E. M., Galinsky, A. D., \& Kray, L. J. (2009). The counterfactual mind-set: A decade of research. In K. D. Markman, W. M. P. Klein, \& J. A. Suhr (Eds.). Handbook of Imagination and Mental Simulation (161-174). Psychology Press. Nova York, NY.

\author{
Endereço para correspondência \\ Juliana Sarantopoulos Faccioli \\ Universidade Federal de São Carlos \\ Laboratório de Desenvolvimento Humano e Cognição (LADHECO) \\ Rodovia Washington Luis, Km 235, Caixa Postal 676, CEP 13.565-905, São Carlos, \\ SP, Brasil \\ Endereço eletrônico: julianasfaccioli@gmail.com
}

Florença Lucia Coelho Justino

Universidade Federal de São Carlos

Laboratório de Desenvolvimento Humano e Cognição (LADHECO)

Rodovia Washington Luis, Km 235, Caixa Postal 676, CEP 13.565-905, São Carlos, SP, Brasil

Endereço eletrônico: florencajustino@gmail.com

Patrícia Waltz Schelini

Universidade Federal de São Carlos

Laboratório de Desenvolvimento Humano e Cognição (LADHECO)

Rodovia Washington Luis, Km 235, Caixa Postal 676, CEP 13.565-905, São Carlos, SP, Brasil

Endereço eletrônico: patriciaws01@gmail.com

Recebido em: 05/08/2014

Reformulado em: 11/11/2014

Aceito para publicação em: 01/12/2014

\title{
Notas
}

* Possui graduação em Psicologia pela Universidade Federal de São Carlos (2010) e mestrado em Psicologia pela mesma instituição (2013). Atualmente é doutoranda da Universidade Federal de São Carlos. Tem experiência na área de Psicologia, com ênfase em Processos Cognitivos e Desenvolvimento, atuando principalmente nos seguintes temas: psicologia educacional, pensamento contrafactual e imaginação.

** Possui graduação em Psicologia pela Universidade Federal de São Carlos (2011) e mestrado em Psicologia pela mesma instituição (2014). É doutoranda da Universidade Federal de São Carlos. Tem experiência na área de Psicologia com ênfase em Processos Cognitivos e Comportamentais, atuando principalmente nos temas: pensamento contrafactual, imaginação e psicologia clínica comportamental. *** Pós-doutora pela Universidade do Minho (Portugal), sob a orientação do Prof. Dr. Leandro da Silva Almeida. É Professora Associada 1 do Departamento de Psicologia da Universidade Federal de São Carlos, onde ministra aulas na graduação e na pós-graduação e desenvolve estudos sobre a inteligência/cognição, metacognição e pensamento imaginativo. 
1 O presente trabalho recebeu financiamento sob forma de bolsa de estudos de Mestrado, concedido pela CAPES, e financiamento do tipo Auxílio Regular e Bolsa de Mestrado pela FAPESP, processos no. 2013/11439-3 e no. 2012/02231-7.

\section{Anexos}

\section{ESTÓRIA 1: A Tentação}

Uma grande amiga sua, que é um pouco tímida com rapazes, te convida para ir com ela e com um rapaz, o João, a uma festa. Como de costume, você aceita o convite. Ultimamente, sua amiga e João estão passando muito tempo juntos, porém, esta foi a primeira vez que eles combinaram de sair à noite. Antes de saírem, sua amiga te conta que está perdidamente apaixonada por ele.

Durante a festa, você percebe que João é muito atraente e, além disso, está interessado em você, e isso te agrada muito. No fim da noite, sem pensar, você passa o seu número de telefone para ele. Quando chega o fim de semana, João telefona e te convida para jantar. Você acaba aceitando o convite. Pouco antes de você sair de casa, sua amiga telefona e conta chorando que João evitou falar com ela durante toda a semana e cancelou a ida ao cinema que haviam combinado antes da festa porque tinha muita coisa para fazer.

Adaptada de Juhos, C., Quelhas, A. C., \& Senos, J (2003)

\section{ESTÓRIA 2 - No caminho de casa}

Ao sair do trabalho, pelo caminho de sempre, Daniel chega muito tarde em casa por conta de uma série de eventos que acontecem em seu caminho. Primeiro, encontra uma árvore muito grande que havia caído e bloqueado a rua que levava até sua casa.

Vendo a rua bloqueada, Daniel resolve mudar o caminho e vira a esquina para fugir do trânsito. Ao mudar sua rota, Daniel encontra um amigo indo para um bar e resolve parar para tomar uma cerveja. Após 20 minutos, Daniel volta a seguir o caminho de casa. Quando finalmente está indo para casa, é surpreendido por um ataque de asma e tem que parar por mais tempo até voltar a respirar normalmente. Quando chega em casa, encontra sua filha desesperada dizendo que sua esposa foi levada ao hospital pelos vizinhos porque tinha sofrido um ataque cardíaco há alguns minutos atrás.

\section{ESTÓRIA 3 - Dilema da Montanha}

Adaptada de Byrne, R. (2005).

Até o quarto dia de escalada de Luiz e Marcos estava tudo bem. Os colegas estavam amarrados um ao outro por uma corda, que, em caso de queda, podia ajudar a salvar a vida do parceiro. Após enfrentar avalanches, nevascas, frio intenso e queda da temperatura corporal nos dois primeiros dias, o terceiro dia de escalada amanheceu com o tempo bom e eles conseguiram alcançar o topo da montanha.

Só faltava descer e, em um ou dois dias, estariam de volta ao acampamento. Quando desciam de volta, nuvens começaram a se aproximar rapidamente, era uma avalanche enorme se aproximando. Tudo o que enxergavam era um branco sem fim e em menos de uma hora, estavam perdidos. Escureceu, e o plano de descer no mesmo dia não deu certo.

Quando voltaram a tentar descer, Luiz caiu e o impacto quebrou sua perna. Marcos devia deixar o amigo para trás, ou morreria junto, mas ele ficou e tentou salvar o amigo. Sentava-se num buraco na neve enquanto esperava que Luiz descesse pela corda. E de corda em corda continuaram a descida.

Foi então que Luiz sem perceber caiu em um precipício, numa fenda gigante que 
dava para um abismo. Ficou preso pela corda que estava amarrada a Marcos e, numa tentativa de se salvar, tentou subir pela corda que o prendia, mas não conseguiu. Marcos começava a se desesperar lá do alto, pensava que se Luiz caísse ele cairia junto. Ficou mais de uma hora sem saber o que fazer e temendo que fosse arrastado pelo amigo. Foi então que Marcos resolveu cortar a corda, deixando Luiz cair no abismo e, por achar que o amigo estava morto, foi embora.

Luiz havia sobrevivido, mas com a perna quebrada era impossível subir pela corda. Então tomou uma decisão corajosa: desceu mais para dentro da fenda, na esperança de encontrar outra saída. Ali encontrou uma espécie de rampa, que levava a outra saída. Ao sair, Luiz viu as pegadas deixadas por Marcos e começou uma jornada de quase 3 dias, rastejando até o acampamento, desidratado, sem comida e com a pele queimada do sol e do gelo.

Quando conseguiu chegar ao acampamento, Marcos ainda estava lá. Passados 2 anos e 6 cirurgias, voltou a escalar e não parou mais.

Adaptado do artigo Supere da Revista Super Interessante. Edição Especial. Dez/2011

\section{ESTÓRIA 4 - Renascido para Viver}

"Foi a melhor coisa que aconteceu", vive dizendo Lauro. Ele não se refere aos prêmios que o tornaram recordista no ciclismo, mas ao câncer que descobriu quando tinha 25 anos. O câncer nos testículos chegou ao pulmão e ao cérebro e o forçou a se aposentar do esporte que já era parte de sua rotina. As chances de recuperação eram de $50 \%$ e, as chances de voltar a ser atleta, nulas. Foi então que ele se agarrou a uma ideia: "a dor que sinto é temporária. Pode ser um minuto, uma hora, um dia, um ano e, no final das contas, vai acabar e dar lugar a outra coisa. Já, se eu desistir, durará para sempre".

Seu corpo já era uma máquina - enquanto os melhores maratonistas conseguem usar em média 70 mililitros de oxigênio por segundo a cada quilo de massa corporal, Lauro usava 85. Mas um atleta não é pura genética, sobreviver trouxe a ele o que faltava: disciplina e obstinação.

Dois anos depois, Lauro mostrou que não costuma desanimar frente aos desafios e voltou a pedalar. Bastou mais um ano para vencer os 6630 quilômetros da volta da França, principal prova de ciclismo mundial. De 2000 a 2005 tornou-se o principal vencedor dessa competição.

Durante esses anos, outro fantasma pairou na sua vida, além do câncer já superado, um ex-colega afirmou que ele usava hormônio do crescimento, testosterona e uma droga que melhora o transporte de oxigênio. Porém, os exames deram negativo e mesmo após as acusações de doping, Lauro participou da corrida mais importante da França, ganhando o prêmio por sete vezes consecutivas.

Em 2005 resolveu se aposentar para se dedicar aos 5 filhos - 3 por inseminação artificial, com o sêmen congelado antes da quimioterapia e dois que vieram naturalmente, apesar de isso ser considerado raro em quem faz esse tipo de tratamento. Em 2009, com 37 anos, disputou a volta da França novamente, ficando em 30 lugar. Só em 2011, quase aos 40, decidiu se aposentar de vez, feliz com o modo como sua carreira começou e terminou.

Adaptado do artigo Supere da Revista Super Interessante. Edição Especial. Dez/2011 